Brit. J. industr. Med., 1948, 5, 77

\title{
STUDIES IN OCCUPATIONAL MORBIDITY (2)
}

\author{
BY \\ IAN SUTHERLAND and G. P. B. WHITWELL \\ From the Institute of Social Medicine, Oxford
}

(RECEIVED FOR PUBLICATION, DECEMBER 22, 1947)

The first paper in this series, which was published in this Journal in 1947 (vol. 4, No. 1, p. 56), contained an analysis of the absenteeism due to sickness and accidents recorded in a particular industrial organization in 1944. It was emphasized that, in view of imperfections in the records which were kept, the investigation should be regarded only as a pilot study: From the beginning of 1946 improvements were made in the system of recordkeeping. The factory in question adopted the individual record card recommended by the Industrial Health Research Board (Report No. 85) for use in large organizations. As a consequence the statistics could be more readily analysed. But the most important results of the change were the greater precision and detail in the information which the cards contained.

\section{Data of Present Study}

The present study covers a wider field than did its predecessor, since it relates to the sickness experience of two factories during 1946. One of these, which will be referred to as A, formed the basis for the previous investigation. This factory is concerned with assembling finished products. The second factory (B) is primarily engaged in manufacture and so represents different types of occupation. For this reason a comparison between the factories is of interest.

The chief extension of the analysis is that absence due to certified sickness is in the present instance classified into seven main cause-groups. Further, the incidence amongst the weekly and monthly clerical staffs can be compared with that in the production and non-production departments (referred to jointly as the works departments). The data were analysed month by month, and hence seasonal changes are also demonstrated.
It may be of interest at the outset to sketch the procedure which has been evolved at this Institute for dealing with the analysis of the sickness records of the two factories during the year. Shortly after the end of each month the record cards, completed to date, were sent to us, and the following general principles were observed in abstracting the data for that month.

1. In estimating the population at risk, entrants and leavers during the month were each counted as half a unit.

2. The days of exposure to risk were based on a sixday week. Sundays and other holidays were ignored. Entrants and leavers were each credited with half a working month.

3. In assessing days lost from sickness, Sundays and other holidays were not counted.

4. In assessing the number of occurrences, an absence continuing from the previous month was not counted as an occurrence in the current month. The days lost therein were, however, debited to it.

5. Certified sickness absences were classified into the seven broad groups recommended by the Industrial Health Research Board. All uncertified absences attributed to sickness were placed in an eighth group. The grouping is as follows :

Group Description
I Colds and influenza
II Diseases of the respiratory system
III Diseases of the digestive system
IV Rheumatism group
V
VI
Vinctional nervous disorders
VII Other certified conditions
VIII Uncertified sickness

The Industrial Health Research Board report No. 85 gives the detailed constitution of Groups I to VII.

The management of each factory received a monthly analysis showing the percentage of possible time lost in each department or shop of their factory from the stated groups of causes, for males and females separately. 
This analysis was accompanied by a brief commentary on the salient features of the month's experience.

The procedure outlined above combines the requirements of the monthly analysis with those of the annual survey. For the latter the population at risk was obtained by averaging the monthly figures; and the days exposed to risk, the days lost through sickness, and the number of occurrences were obtained by aggregating the monthly values.

The average size of the population in each factory during the year 1946 was as follows :

\begin{tabular}{|c|c|c|c|}
\hline \multirow{3}{*}{$\begin{array}{l}\text { Factory A (including staff) } \\
\text { Factory B (excluding staff) }\end{array}$} & Males & Females & Total \\
\hline & 3,395 & 542 & 3,937 \\
\hline & & 201 & 1,147 \\
\hline & 4,341 & 743 & 5,084 \\
\hline
\end{tabular}

The Necessity to Standardize Rates

It is now well recognized that the age and sex composition of a factory population has an appreciable influence upon its total morbidity rate. The extent to which the age-factor operates is indicated in Table 1 , which shows the number of absences due to certified sickness per 100 male employee-years, in each of five age-groups. The incidence is similar in the two factories. In each the lowest value occurs in the age-group 25 to 34 . Thereafter the rates increase with age, and at ages 55 and over attain a value of 69.7 per 100 employees in factory $A$ and 58.6 in factory $B$. The rates in the final age-group are in both factories double those in the group aged 25 to 34. The figures thus suggest a steeper rise in incidence with age than those collected by Padley (1947).

It is obvious that the elimination of the effects of age is essential in forming an adequate and satisfactory index of total morbidity. This is done by the established method of direct standardization. The population chosen as the most suitable standard was that of factory A during 1946, and it has been used to standardize the rates presented in this paper. Its proportional distribution is as follows :

$$
\begin{aligned}
& \text { Age Group } \\
& \text { 15-24 . . . . } 1,413
\end{aligned}
$$

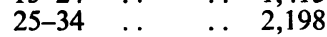

$$
\begin{aligned}
& 35-44 \quad \ldots \quad \ldots \quad 2,956 \\
& \text { 45-54 } \quad . . \quad \ldots .2,363 \\
& \begin{array}{llll}
55+ & \ldots & \ldots & 1,070
\end{array} \\
& 10,000
\end{aligned}
$$

\section{Standard Errors}

It is usual and desirable in presenting figures to give some indication of the chance fluctuation to which they are subject in order that real differences may be separated from unimportant ones. This is generally done by assigning a standard error of sampling to each figure. The absence of such criteria from certain of the ensuing tables, particularly Tables 2 and 3, may be remarked upon.

The determination of standard errors for such sickness rates raised many difficulties, both practical and theoretical. In view of these, it was decided that it would be unwise to attach to the rates figures which might not be accurate measures of sampling fluctuation, yet which by their presence would give the impression of reliability. Some of these difficulties are indicated below.

Percentages, such as those in Table 4, are known (theoretically and in practice) to follow a binomial distribution, and their standard errors may readily be calculated from the formula $\sqrt{\mathbf{P}(100-P) / N}$, where $P$ is the percentage of the population with a certain characteristic and $\mathbf{N}$ the size of the population on which it is based. (It may be noted in passing that a rate which is standardized for age requires a standard error which is also agestandardized. In such circumstances the above formula must be replaced by a modified one.) There are unfortunately no valid theoretical bases for assuming sampling distributions for the sickness rates in question. It will be recalled that in the previous paper a negative binomial distribution was shown to fit the distribution of occurrences among individuals. It might be argued that this information provides a practical basis for the estimation of standard errors for occurrence rates. The distribution, however, relates only to those workers who had been employed for the complete year. The 1946 population includes a high proportion of entrants and leavers (nearly equal in number to those continuously employed) and so cannot be regarded as comparable. The presence of employees who each contribute less than one employeeyear to the sum experience must have repercussions on the sampling distributions of the rates in Tables 2 and 3, which are both based upon units of employee-years.

These and other considerations, coupled with severe practical difficulties (which for example, made it impossible to derive any standard errors for factory $B$ even if the theoretical path had been smooth), led to the decision not to attempt to estimate any standard errors for the main sickness rates presented below. It is clear that more investigation is needed, at both theoretical and practical levels, to establish a more reliable basis for the problems raised.

TABLE 1

OCCURRENCES OF CERTIFIED SICKNESS PER 100 EMPLOYEEYEARS, IN AGE-GROUPS: WORKS DEPARTMENTS OF FACTORIES A AND B.

MALES, 1946

\begin{tabular}{c|c|c}
\hline Age in years & Factory A & Factory B \\
\hline $15-24$ & $36 \cdot 9$ & $42 \cdot 4$ \\
$25-34$ & $34 \cdot 4$ & $26 \cdot 9$ \\
$35-44$ & $42 \cdot 0$ & $38 \cdot 2$ \\
$45-54$ & $49 \cdot 8$ & $50 \cdot 4$ \\
$55+$ & $69 \cdot 7$ & $58 \cdot 6$ \\
\hline Average population & 3,005 & \\
at all ages & & 946 \\
\hline
\end{tabular}

Incidence of Sickness Absence

The first set of findings to be considered relates to the incidence of sickness among the employees. 
TABLE 2

NUMBER OF OCCURRENCES OF CERTIFIED SICKNESS PER 100 EMPLOYEE-YEARS, 1946 (RATES STANDARDIZFD FOR AGE)

\begin{tabular}{|c|c|c|c|c|c|c|c|c|c|c|}
\hline \multirow{3}{*}{\multicolumn{2}{|c|}{ Sickness group }} & & \multicolumn{6}{|c|}{ Factory A } & \multirow{2}{*}{\multicolumn{2}{|c|}{$\frac{\text { Factory B }}{\text { Works }}$}} \\
\hline & & & \multirow{2}{*}{$\frac{\text { Prod. }}{\mathrm{M}}$} & \multirow{2}{*}{$\begin{array}{c}\begin{array}{c}\text { Non- } \\
\text { prod. }\end{array} \\
\mathbf{M}\end{array}$} & \multicolumn{2}{|c|}{ Works } & \multicolumn{2}{|c|}{ Clerical } & & \\
\hline & & & & & $\mathbf{M}$ & $\mathrm{F}$ & $\mathbf{M}$ & $\mathbf{F}$ & $\mathbf{M}$ & $\mathrm{F}$ \\
\hline $\begin{array}{r}\text { I. } \\
\text { II. } \\
\text { III. } \\
\text { IV. } \\
\text { V. } \\
\text { VI. } \\
\text { VII. }\end{array}$ & $\begin{array}{l}\text { Colds, influenza.. } \\
\text { Respiratory diseases } \\
\text { Digestive diseases } \\
\text { Rheumatism group } \\
\text { Nervous disorders } \\
\text { Accidents at work } \\
\text { Other certified condition }\end{array}$ & $\begin{array}{l}\cdots \\
\cdots \\
\cdots \\
\cdots \\
\cdots \\
\cdots\end{array}$ & $\begin{array}{r}5 \cdot 44 \\
2 \cdot 77 \\
5 \cdot 73 \\
4.92 \\
1.97 \\
2 \cdot 11 \\
15 \cdot 05\end{array}$ & $\begin{array}{r}7 \cdot 26 \\
5 \cdot 65 \\
7 \cdot 57 \\
5 \cdot 03 \\
1 \cdot 70 \\
1 \cdot 91 \\
23 \cdot 00\end{array}$ & $\begin{array}{r}6 \cdot 32 \\
4 \cdot 17 \\
6 \cdot 62 \\
4 \cdot 97 \\
1 \cdot 84 \\
2 \cdot 01 \\
18 \cdot 92\end{array}$ & $\begin{array}{r}10 \cdot 36 \\
2 \cdot 09 \\
6 \cdot 40 \\
1 \cdot 64 \\
2 \cdot 74 \\
2 \cdot 64 \\
20 \cdot 24\end{array}$ & $\begin{array}{r}7 \cdot 14 \\
3 \cdot 26 \\
5 \cdot 13 \\
2 \cdot 22 \\
0 \cdot 83 \\
1 \cdot 31 \\
10 \cdot 96\end{array}$ & $\begin{array}{r}11 \cdot 53 \\
5 \cdot 54 \\
7 \cdot 08 \\
5 \cdot 40 \\
2 \cdot 91 \\
3 \cdot 63 \\
52 \cdot 01\end{array}$ & $\begin{array}{r}6 \cdot 59 \\
5 \cdot 08 \\
7 \cdot 51 \\
3 \cdot 18 \\
0 \cdot 66 \\
4 \cdot 77 \\
13 \cdot 57\end{array}$ & $\begin{array}{r}14 \cdot 33 \\
5 \cdot 02 \\
9 \cdot 58 \\
5 \cdot 44 \\
1 \cdot 79 \\
5 \cdot 49 \\
30 \cdot 43\end{array}$ \\
\hline & Total certified absence & . & $37 \cdot 99$ & $52 \cdot 12$ & $44 \cdot 85$ & $46 \cdot 11$ & $30 \cdot 85$ & $88 \cdot 10$ & $41 \cdot 36$ & $72 \cdot 08$ \\
\hline & Average population & . & 1,544 & 1,461 & 3,005 & 242 & 390 & 300 & 946 & 201 \\
\hline
\end{tabular}

The numbers of occurrences of certified sickness during the year per 100 employee-years, distinguishing the seven cause-groups, sex, and grade of work, are stated in Table 2.

It will be noted that the sickness rates for males in the works departments of the two factories are similar; there were 44.9 occurrences per 100 employee-years in factory A and 41.4 in factory $B$. But there was a wide divergence in the comparable rates for females, which were $46 \cdot 1$ and 72.1 respectively. The female population in both factories is small, and so chance fluctuation in the rates is to be expected. Notwithstanding this the difference indicated is appreciable.

Production and Non-Production Work.-The sickness incidence for male employees engaged on production work in factory $A$ is much lower than that for workers in non-production departments38.0 as against $52 \cdot 1$. This difference is in all probability largely due to a selective factor. The men who are on the whole less fit will tend to be employed upon the lighter jobs which are found in non-production departments, and so the general level of health among non-productive workers will be lower than that in the production shops. It is quite probable that some workers will have changed or been moved to non-production work for the very reason that production work was too great a strain upon their health.

Clerical Workers.-The most marked divergence in the Table occurs between the male and female clerical staff in factory A. For the former the rate was $\mathbf{3 0} \cdot 9$, but for the latter it was as high as $88 \cdot 1$. In other words the female incidence was 186 per cent. in excess of that for males engaged on the same type of work. Although the male clerical staff had such a favourable experience, when they are sub-divided into those paid weekly and those paid monthly a considerable difference is observed in the rates (not shown in the Table). The rate for monthly staff was 20.4 per 100 employee-years and for weekly staff 39.8 . Thus the incidence of sickness among the latter was 95 per cent. higher than among the higher-grade workers. It is by no means certain that sickness absence among the monthly staff is fully recorded. The requirement to submit a doctor's certificate is not rigidly enforced for them as it is in the case of weekly wage-earners, and so a proportion of absences among monthly staff may never be recorded by the labour department. It is thus necessary to interpret the observed difference with some caution. If it is a real one, a possible explanation may be a socio-economic factor involving rates of pay and type of work. Bashford (1945) indicated a similar divergence between different grades of Civil Service employees, and commented upon it as follows :

"In this group [those above the rank of clerical officer], an economic factor may be at work in their favour. But it also seems probable that the nature of the actual work performed, which is usually of a more responsible, less routine and more 'brainstretching character is at least an equally important factor. Such work, as all experience tends to show, does appear to enable most people to ignore or disregard minor illnesses and disabilities, which are liable to become much more obtrusive when the work performed is of a relatively routine and monotonous kind, yet at the same time often demanding a high degree of what might be described as uninteresting accuracy; and this applies also to the pre-illness condition of fatigue. It is probably a quite sound 
aphorism that interesting and absorbing work is less fatiguing than work, particularly non-manual work, of a duller and less stimulating type."

Specific Causes of Absence.-When the individual cause-groups are examined it will be seen that the miscellaneous group (VII) is numerically the most important, and that its importance varies with the type of work. Among males engaged in clerical work this group accounted for- 36 per cent. of the total, while for females in the clerical staff it constituted 59 per cent. In practice it would appear that group VII is too comprehensive and should be subdivided into three or four categories.

"Colds and influenza" come next in importance, particularly among female employees, the rates for whom are 10.4 and 11.5 in the works departments and staff of factory $A$, and $14 \cdot 3$ in the works departments of factory B. "Digestive diseases" also make a marked contribution to the total in both factories and in all grades of work. It is of interest that the rate in production shops of factory $A$ is 5.7 as compared with $\mathbf{7 . 6}$ in non-production departments.

The incidence of " accidents at work" in factory $B$ is considerably higher than that in the works departments of factory A. For males the rates are 4.8 and 2.0 respectively. This difference is attributable to the different character of the work undertaken at the two factories.

The incidence of "nervous disorders" is uniformly low-the group is numerically the least important of those specified. The figures are in very striking contrast to those recently published in the report by Russell Fraser (1947) on neurosis in factory workers, although exact comparisons are unfortunately impossible. Russell Fraser's sample consisted of a wartime population of over 3,000 male and female workers from thirteen factories engaged in work very similar to that in factories $A$ and $B$. The study showed that during the course of six months 10 per cent. of those examined had suffered from definite and disabling neurotic illness and a further 20 per cent. from minor forms of neurosis. In the course of a year the incidence of certified nervous disorders in the works departments of factory $\mathbf{A}$ was under 2 occurrences per 100 male employees, and less than 3 occurrences per 100 female employees. The incidence in factory B was even lower.

Turning to time lost, Russell Fraser found that neurosis caused 1.09 per cent. possible time lost among males and 2.40 per cent. among females (certified and uncertified absence combined). These figures represent 25 per cent. and 35 per cent. respectively of the total time lost through sickness and accident. The corresponding values for certified nervous disorders in factory $A$ are 0.08 per cent. possible time lost among males and $0 \cdot 18$ per cent. among females (not tabulated); and these figures represent about 3 per cent. and 6 per cent. respectively of the total time lost from certified sickness and accident.

TABLE 3

NUMBER OF WORKING DAYS LOST PER EMPLOYEE-YEAR FROM CERTIFIED AND UNCERTIFIED SICKNESS, 1946 (RATES STANDARDIZED FOR AGE)

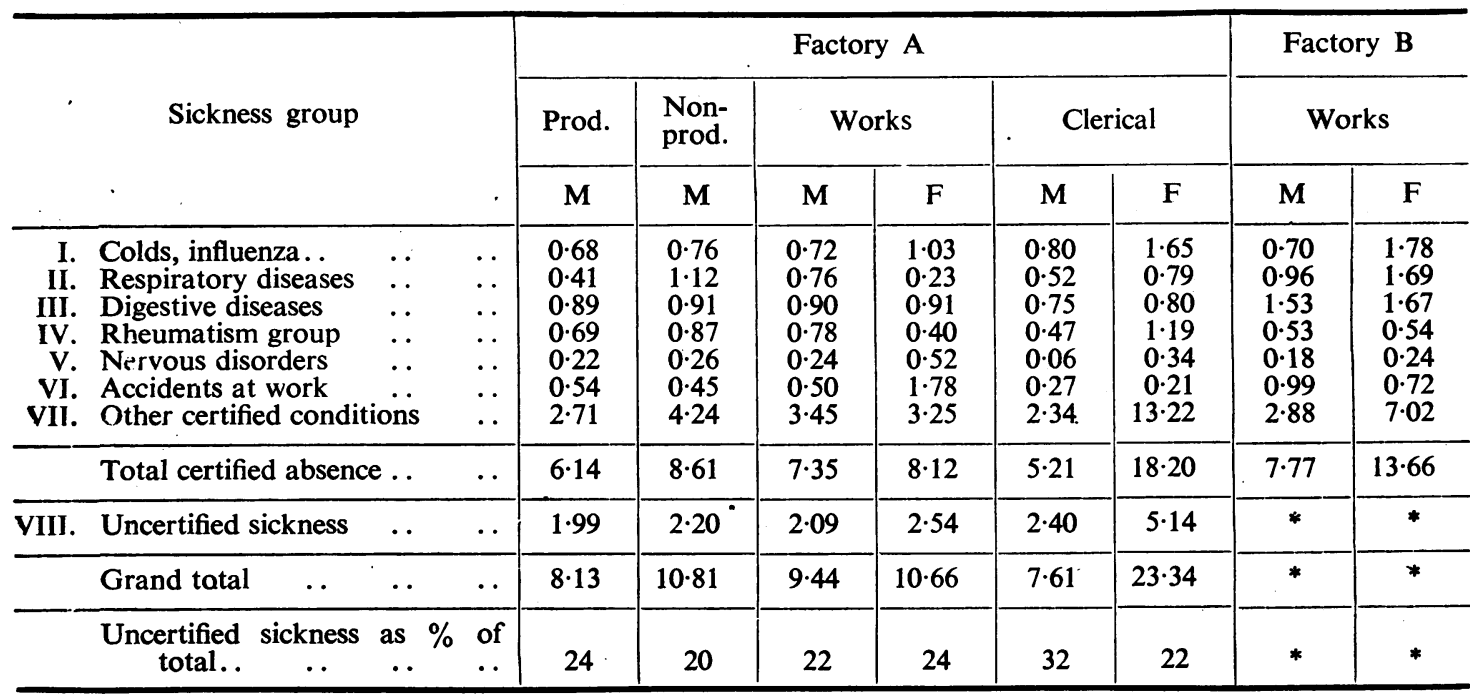

* Rates not available. 
No information is available as to the causes of uncertified absence in factory $\mathrm{A}$, and the difference in the latter findings is doubtless materially accentuated by this fact. It should be noted further that the investigation just cited was specifically directed to the detection of neurosis, and so would be expected to find more than a busy general practitioner does when examining and certifying panel patients. The circumstances are quite different in the two cases, and demand different criteria.

\section{Percentage Time Lost}

The time lost from sickness can be expressed as a rate in a variety of ways. For example, the factory management is interested in the percentage of possible working time which is lost through sickness, as this index gives an overall picture of the importance of sickness absence to the firm. The percentage of possible working days lost from all certified sickness (Groups I to VII) in the various divisions of the two factories is as follows :

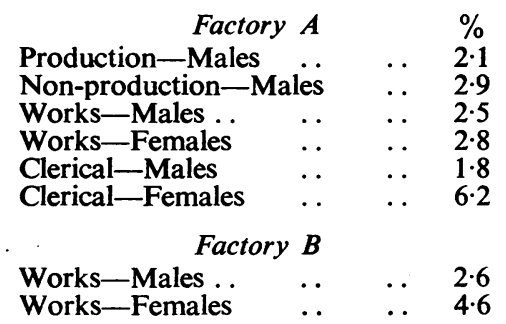

These rates are standardized for age. Since the utility or importance of a standardized rate to a factory management may be questioned, this matter is taken up in greater detail later in this study.

In the works departments of the two factories the rates for males are almost the same -2.5 per cent. and 2.6 per cent.-while for females there is considerable divergence, the rates being 2.8 per cent. in factory A and 4.6 per cent. in factory B. There is a large difference between the male and female staff, for whom the values are 1.8 per cent. and 6.2 per cent. The pattern of these figures is similar to that of the incidence rates.

\section{Days Lost per Employee}

An alternative method of expressing the time lost is in the form of working days lost per employee, and these rates are presented in detail in Table 3.

In the works departments of both factories each male lost on an average a little over a working week (6 days), from all forms of certified sickness, the rates being 7.4 in factory $A$ and $\mathbf{7 . 8}$ in factory $B$. Each female lost 8.1 working days in factory $A$ and 13.7 days (more than a working fortnight) in factory B. The contrast between male and female staff is once more the most outstanding feature of the Table. Whereas for male staff the rate was $5 \cdot 2$ days lost, the rate among the females was over 18 working days. When the male staff are further divided into 'weekly' and 'monthly' staff, the rates (not given in the Table) are $7 \cdot 3$ and $2 \cdot 8$ respectively for these sub-groups.

Specific Causes.-Group VII stands out conspicuously from the other groups of certified sickness as the chief contributor to lost time. The Group VII rate for female clerical staff in factory $A$ is exceptionally high, being $13 \cdot 2$, and this figure represents 70 per cent. of the total time lost from certified sickness in this grade. Next in importance come "colds and influenza" and "digestive diseases." The latter group causes a particularly large amount of lost time in factory B. As was mentioned above, "nervous disorders" are not important as a cause of lost time.

Uncertified Sickness.-The Table also shows the

TABLE 4

PERCENTAGES OF THOSE EMPLOYED THROUGHOUT 1946, WHO HAD NO SICKNESS ABSENCE EITHER CERTIFIED OR UNCERTIFIED IN THAT YEAR : FACTORY A

\begin{tabular}{|c|c|c|c|c|c|c|c|c|c|c|c|}
\hline & & & & \multicolumn{2}{|c|}{ Works } & \multicolumn{2}{|c|}{ Weekly staff } & \multicolumn{2}{|c|}{ Monthly staff } & \multicolumn{2}{|c|}{ Total } \\
\hline & & & & Pop. & $\%$ & Pop. & $\%$ & Pop. & $\%$ & Pop. & $\%$ \\
\hline Males & .. &. &.. & 1981 & 37 & \multirow[t]{3}{*}{118} & 28 & 192 & \multirow[t]{3}{*}{55} & 2291 & 38 \\
\hline Females & & & & & & & Pop. & $\%$ & & & \\
\hline $\begin{array}{l}\text { Mariied } \\
\text { Single }\end{array}$ &.. &. &.. & $\begin{array}{l}80 \\
63\end{array}$ & $\begin{array}{l}16 \\
21\end{array}$ & & $\begin{array}{r}46 \\
154\end{array}$ & $\begin{array}{l}15 \\
14\end{array}$ & & $\begin{array}{l}126 \\
217 \\
\end{array}$ & $\begin{array}{l}16 \\
16 \\
\end{array}$ \\
\hline All females & . &. &. & 143 & 18 & & 200 & 14 & & 343 & 16 \\
\hline
\end{tabular}


days lost per employee from uncertified sickness. In the works departments of factory A the rates for males and females were $2 \cdot 1$ and 2.5 working days respectively. Among the clerical workers the difference was much greater, the figures being 2.4 and 5.1. The final line of the Table shows that uncertified sickness is on the whole responsible for between 20 per cent. and 25 per cent. of the time lost from all sickness. Among the male staff, however, the corresponding figure was higher than 30 per cent.

\section{No Sickness Absence}

In studying the morbidity of a factory population, an incomplete picture is given by considering merely those employees who are sick. It is equally instructive to ascertain what proportion of employees had no sickness absence over a given period. 'An analysis was made of those who were employed throughout the whole year 1946, and the percentages who had no sickness absence, certified or uncertified, during the year are stated in Table 4. The main contrast is the high proportion of. males; as compared with females, who had no sickness absence. The figures are 38 per cent. and 16 per cent. respectively.

The statistical experience of males in the works departments, who comprise the bulk of the male employees, accords closely with the general average for males, as would be expected. But the clerical staff show an interesting variation : only 28 per cent. of the weekly staff escaped sickness during the year, whereas 55 per cent. of the monthly staff did so. As indicated earlier, there is reason to believe the sickness records of the monthly staff may be incomplete, and so it is unwise to attach too much importance to the difference.

Although the total female population is small, it is of interest that no significant difference is observable between the experience of single and married women either in works departments or in the staff. In the whole factory the rate for each is 16 per cent.

In conclusion it may be mentioned that the contrast between the experience of males and females in the factory as a whole disappears when the percentages of employees with no certified sickness absence in 1946 are calculated; 33 per cent. of the males had uncertified sickness only during the year as against 54 per cent. of the female employees. Thus 71 per cent. of males had no sickness serious enough to require a certificate, and this agrees closely with the corresponding figure of 70 per cent. for females.

TABle 5

AVERAGE DURATION OF ABSENCE FROM CERT́IIFIED SICKNESS, IN WORKING DAYS AND RELATIVE IMPORTANCE OF LONG AND SHORT ABSENCES, $\dagger 1946$ (AVERAGE DURATION RATES STANDARDIZED FOR AGE)

\begin{tabular}{|c|c|c|c|c|c|c|}
\hline . & Part of factory & Sickness group & $\begin{array}{l}\text { Number } \\
\text { of occur- } \\
\text { rences }\end{array}$ & $\begin{array}{c}\text { Average } \\
\text { absence } \\
\text { (days) }\end{array}$ & $\begin{array}{l}\text { Percentage of } \\
\text { occurrences } \\
\text { which } \\
\text { involved long } \\
\text { absences }\end{array}$ & $\begin{array}{l}\text { Time lost in } \\
\text { long absences } \\
\text { as a per- } \\
\text { centage of } \\
\text { total time lost }\end{array}$ \\
\hline \multirow[t]{5}{*}{ Factory A } & $\begin{array}{l}\text { Production-males } \\
\text { Non-prod.-males }\end{array}$ & $\begin{array}{l}\text { All certified } \\
\text { All certified }\end{array}$ & $\begin{array}{l}569 \\
796\end{array}$ & $\begin{array}{l}15 \cdot 9 \\
16 \cdot 4\end{array}$ & * & * \\
\hline & \multirow[t]{2}{*}{ Works-males } & $\begin{array}{l}\text { I. Colds, influenza } \\
\text { II. Respiratory disorders } \\
\text { III. Digestive disorders } \\
\text { IV. Rheumatic group } \\
\text { V. Nervous disorders } \\
\text { VI. Accidents at work } \\
\text { VII. Other certified con- } \\
\text { ditions }\end{array}$ & $\begin{array}{r}195 \\
143 \\
205 \\
160 \\
55 \\
58 \\
549\end{array}$ & $\begin{array}{l}11 \cdot 3 \\
16 \cdot 8 \\
13 \cdot 3 \\
15 \cdot 8 \\
13 \cdot 3 \\
26 \cdot 1 \\
17 \cdot 9\end{array}$ & $\begin{array}{r}2 \cdot 1 \\
18 \cdot 9 \\
8 \cdot 3 \\
11 \cdot 9 \\
7 \cdot 3 \\
32 \cdot 8 \\
14 \cdot 6\end{array}$ & $\begin{array}{l}12 \cdot 1 \\
58 \cdot 9 \\
38 \cdot 3 \\
42 \cdot 2 \\
37 \cdot 5 \\
85 \cdot 5 \\
51 \cdot 6\end{array}$ \\
\hline & & All certified & 1365 & $16 \cdot 2$ & $12 \cdot 5$ & $47 \cdot 4$ \\
\hline & Works-females & All certified & 104 & $16 \cdot 8$ & $9 \cdot 6$ & $39 \cdot 1$ \\
\hline & $\begin{array}{l}\text { Clerical-males } \\
\text { Clerical_females }\end{array}$ & $\begin{array}{l}\text { All certified } \\
\text { All certified }\end{array}$ & $\begin{array}{l}126 \\
152\end{array}$ & $\begin{array}{l}16 \cdot 0 \\
22 \cdot 1\end{array}$ & $\begin{array}{l}15 \cdot 9 \\
14 \cdot 5\end{array}$ & $\begin{array}{l}54 \cdot 1 \\
57 \cdot 5\end{array}$ \\
\hline Factory B & $\begin{array}{l}\text { Works-males } \\
\text { Works-females }\end{array}$ & $\begin{array}{l}\text { All certified } \\
\text { All certified }\end{array}$ & $\begin{array}{l}385 \\
130\end{array}$ & $\begin{array}{l}17 \cdot 9 \\
18 \cdot 7\end{array}$ & * & * \\
\hline
\end{tabular}

- Figures not available.

† For definition of a long absence, see text. 


\section{Duration of Illness}

To add further to the picture of morbidity in the two factories for the year, the mean duration of absence from certified sickness was calculated and the figures are given in Table 5. Owing to the small numbers of occurrences in some sub-groups this Table is not presented in as great detail as Tables 2 and 3.

In the works departments, the average duration of absence of male employees is slightly higher in factory $B$ than in factory $A$, the respective durations being 17.9 days and 16.2 days. There is a similar difference for females who had rates of 18.7 and 16.8 days in the two factories. Thus there is little sex-disparity in the works. But among the staff in factory $\mathrm{A}$, while the duration of absence of males is 16.0 days, for females it is longer by 6.1 days. It will be seen that among males in the works departments of factory A "colds and influenza" have the shortest duration while "accidents at work" have the longest ; the figures being 11.3 and $26 \cdot 1$ days respectively.

Long and Short Absences.-The mean duration of sickness absence, by itself, may give a misleading picture, as it will be unduly affected by long-term illness. It is thus essential, and instructive, to divide all absences into 'short' and 'long,' and to determine the relative importance of the two types. The dividing line between the two is obviously quite arbitrary. In this study an absence has been classed as ' long' if it caused a loss of $\mathbf{3 0}$ or more working days during 1946 . In this connexion it should be mentioned that certain of the employees in factory $\mathrm{A}$-between 20 and 30 in number-are regarded by the management as 'permanently sick.' These are workers undergoing sanatorium treatment for tuberculosis, or in mental hospitals, or in similar circumstances where it is most unlikely that the man will return to work, if at all, for a considerable time. Although such workers remain on the books of the firm, they have been excluded from the analysis in this paper on the grounds that they contribute neither to the true population at risk nor to a study of current sickness absence. This fact should be borne in mind in reading the final two columns of Table 5, which show for factory $A$ the percentage of occurrences which involved long absence together with the percentage of total time lost which was due to long absences.

In the works departments of the factory, 12.5 per cent. of occurrences among males and 9.6 per cent. among females, led to absences of 30 days or more in 1946. This difference may easily have arisen by chance, considering the small number of occurrences among the females. Among the staff the corresponding percentages were 15.9 per cent. for males and 14.5 per cent. for females. Long absences accounted for between 39 per cent. and 58 per cent. of all the lost time from sickness in the factory.

Specific Causes.-There is considerable variation in the proportion of long absences between the various disease groups into which the males in the works departments are subdivided. The lowest percentage occurs in Group I- " colds and influenza," in which only $2 \cdot 1$ per cent. of the absences lasted for 30 days or over. "Digestive diseases" and " nervous disorders" also have a low percentage of long absences. At the other end of the scale, no less than 32.8 per cent. of the lost-time accidents involve an absence of 30 or more days from work. "Respiratory diseases" also show a high figure18.9 per cent.

The percentage of lost time which is due to long absences follows a similar pattern with disease group and ranges from $12 \cdot 1$ per cent. for "colds and influenza " to 85.5 per cent. for " accidents at work."

\section{Interpretation of the Tables}

At this stage it is as well to take up one particular finding of the Tables which is liable to misinterpretation. In discussing Tables 2,3 , and 5 , special attention was drawn in each case to the marked disparity between the statistical experience of the male and female clerical staff in factory A. Before accepting the conclusion that female clerical labour is, because of these high sickness rates, economically or otherwise disadvantageous, two points must be clearly understood.

In the first place, while the male staff consists roughly of equal numbers of weekly and monthly staff, the female staff is with few exceptions made up of weekly wage-earners. It has been indicated earlier in this paper that the male monthly staff has very low sickness as compared with the male weekly staff. Thus for a fair comparison between the sexes weekly staff should be set against weekly staff. In the Tables, like has not been compared with like, because the populations involved are so small.

In the second place, the age-factor must be borne in mind, as it is of particular importance in relation to male and female staff. In the standard population used in this study, 14 per cent. of the total are in the age-group 15 to 24 . The percentage of male weekly staff of factory $A$ in this age-group is 36 per cent., while the corresponding figure for the female weekly staff is 64 per cent. Thus not only do the staff age-distributions differ from the standard, but they differ widely from one another.

From the standpoint of the scientific investigator, 
TABLE 6

CRUDE AND AGE-SPECIFIC RATES FROM ALL CERTIFIED SICKNESS : FACTORY A, 1946

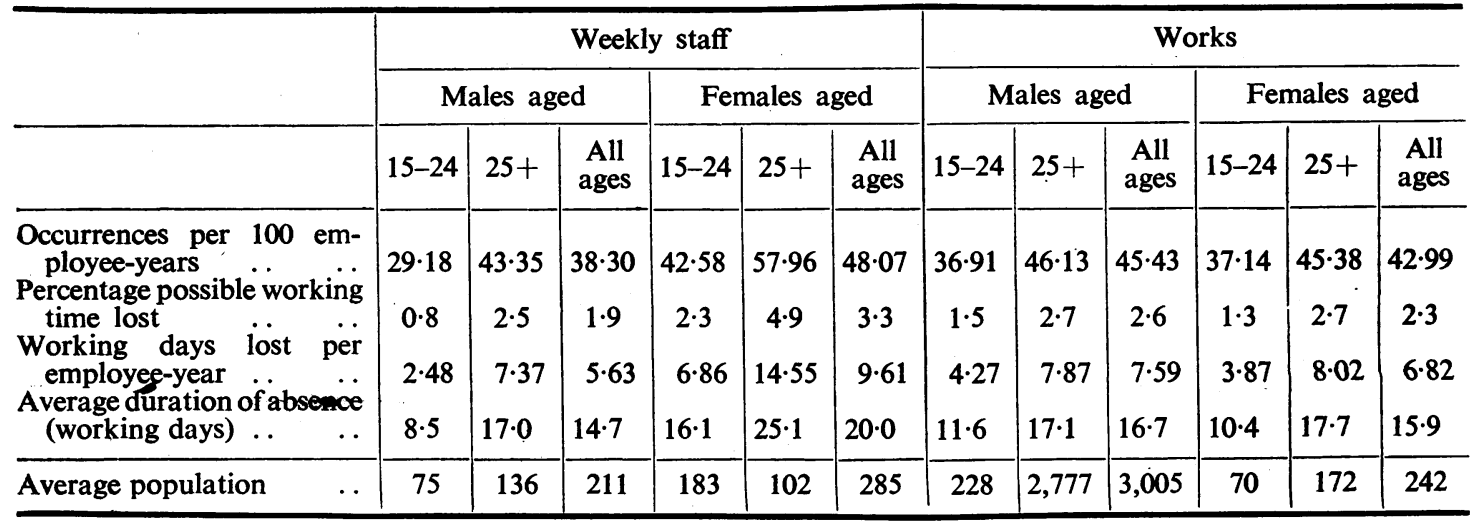

this fact makes standardization imperative if he is to gain a comparable picture of sickness in the two groups, independent of the effects of age. From the point of view of the factory management, the same fact renders standardized rates virtually meaningless, as they may differ so widely from the crude rates. To draw a gloomy parallel, a crude death-rate is of greater import to a gravediggers' union than is a standardized rate. The factory is not interested in the sickness rates that would occur in a male and female weekly staff, each with 14 per cent. in the age-group 15 to 24 . The management is concerned with the rates actually occurring in the male and female staff, in other words with the crude rates and age-specific rates.

To meet these requirements Table 6 has been prepared; it compares the experience of the male and female weekly staff in two age-groups. It will be seen that the sex-difference suggested in the standardized rates above is also shown by these rates. At all ages there were 48.1 occurrences per 100 female weekly staff as against 38.3 per 100 male weekly staff ; 9.6 working days were lost per female employee and 5.6 days per male employee in the year. When the data are considered in age-groups the sex-difference is seen to persist, showing that it is not dependent on the different age-distributions of the two staffs. It may be concluded that not only are there inherently greater sickness rates among female staff (as shown by the standardized rates), but that there are also higher crude sickness rates when the age-distributions are those encountered in practice.

This is not yet a complete picture from the point of view of the factory. It has been shown that despite a more favourable age-distribution more sickness actually occurs, and leads to more lost time, in female clerical staff than in male. How. then, do the actual sickness rates among the staff compare with those in the works? The second part of Table 6 provides an answer.

Among males the weekly staff have more favourable crude sickness rates than in the works. The respective occurrence rates are 38.3 and 45.4 and the 'days lost' rates are 5.6 and 7.6. Comparison of the separate age-groups reveals the same picture.

Turning to the female experience, the position is reversed; the crude occurrence rates are 48.1 in the weekly staff and 43.0 in the works. The respective 'days lost' rates are 9.6 and 6.8. Once more the data for individual age-groups confirm the general experience.

To sum up the findings from the point of view of the factory management, the four groups considered here may be placed in the following order, with increasing crude sickness absence rates : male weekly staff, females in works departments, males in works departments, and female weekly staff. The range in the crude occurrence rates is only from 38 to 48 , whereas in the standardized rates it is much greater. Thus the differences in age-distribution between sections of the factory tend to bring the crude sickness rates closer together.

\section{Seasonal Incidence}

The seasonal incidence of absenteeism due to sickness in the two factories, measured by the percentages of possible working time lost in various periods of the year, is shown by Table 7. Figures for males only are presented. The rates for females are much less dependable as they are based on a small population, and they have been omitted. In the main, however, the seasonal patterns for females are similar to those for males. 
TABLE 7

PERCENTAGES OF POSSIBLE WORKING DAYS LOST AT DIFFERENT SEASONS (UNSTANDARDIZED RATES) : MALES IN FACTORIES A AND B COMBINED, 1946

\begin{tabular}{ll|l|l|l|l|l|l|l|l|l|l|l|l|l}
\hline & Jan. & Feb. & Mar. & Apr. & May & June & July & Aug. & Sept. & Oct. & Nov. & Dec. \\
\hline All certified absence &. & 3.32 & 4.04 & 3.39 & 2.34 & 2.31 & 2.08 & 1.95 & 2.43 & $2 \cdot 16$ & 2.50 & 2.48 & 2.44 \\
\hline
\end{tabular}

\begin{tabular}{|c|c|c|c|c|c|c|}
\hline \multicolumn{3}{|l|}{ Sickness group } & 1st Quarter & 2nd Quarter & 3rd Quarter & 4th Quarter \\
\hline $\begin{array}{l}\text { I. Colds, influenza } \\
\text { II. Respiratory diseases } \\
\text { III. Digestive diseases } \\
\text { IV. Rheumatism group } \\
\text { V. Nervous disorders .. } \\
\text { VI. Accidents at work . } \\
\text { VII. Other certified conditions } \\
\text { VIII. Uncertified sickness (Fact }\end{array}$ & $\begin{array}{cc}\because & \cdots \\
\cdots & \cdots \\
\cdots & \cdots \\
\cdots & \cdots \\
\cdots & \cdots \\
\text { tory } & \cdots \\
\text { A only) }\end{array}$ & 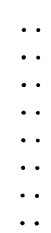 & $\begin{array}{l}0.68 \\
0.57 \\
0.39 \\
0.44 \\
0 \cdot 11 \\
0 \cdot 19 \\
1.21 \\
0.90\end{array}$ & $\begin{array}{l}0 \cdot 14 \\
0 \cdot 25 \\
0 \cdot 27 \\
0 \cdot 19 \\
0 \cdot 07 \\
0 \cdot 20 \\
1 \cdot 12 \\
0 \cdot 55\end{array}$ & $\begin{array}{l}0 \cdot 10 \\
0 \cdot 12 \\
0 \cdot 33 \\
0 \cdot 23 \\
0.04 \\
0 \cdot 26 \\
1.09 \\
0.54\end{array}$ & $\begin{array}{l}0.13 \\
0.30 \\
0.43 \\
0.25 \\
0.09 \\
0.23 \\
1.06 \\
0.74\end{array}$ \\
\hline
\end{tabular}

For the total certified absence there is a clear seasonal trend. From a peak value in February of 4.04 per cent., the rate drops steeply to 2.34 per cent. in April, and then declines slowly to a minimum value of 1.95 per cent. in July. From August to December the rate is above the July figure but shows no decided trend.

As regards the individual groups of certified sickness, the figures are presented quarterly to minimize chance variations. "Colds and influenza" and "respiratory diseases" show the same trend as the total sickness, but in an enhanced degree. This is particularly true of colds and influenza, from which 0.68 per cent. working time is lost in the first quarter of the year and only 0.10 per cent. in the third. Digestive diseases (Group III) return their highest rate in the fourth quarter, but show no pronounced seasonal trend. With the exception of " accidents at work" the remaining groups all return their highest incidence in the first quarter. The picture for accidents is dissimilar from the rest in that they lead to least lost time in the first quarter and have raised rates during the summer.

For uncertified sickness (Group VIII) the rates for factory A alone, which are also presented quarterly, tend to follow the same pattern as the total certified sickness in the two factories, with a maximum of 0.90 per cent. in the first quarter and a low rate of 0.54 per cent. during the summer.

\section{Sickness Proneness}

Attention was drawn in the previous paper to evidence in favour of the existence of 'sickness proneness' analogous to the well-recognized phenomenon of 'accident proneness.' As in 1944 frequency distributions were made for males and females who had been employed for the whole of 1946 in factory A. (Unfortunately a change in the method of record-keeping during the year precluded a similar analysis for factory B.) For the females, a Poisson distribution (arising from the hypothesis of equal liability of workers to ' go sick') corresponds well with that observed. This does not agree with the 1944 finding, but it should be observed that the female population employed in factory A throughout 1946 was only 343 , as against 552 in the earlier year.

For males, the Poisson distribution again did not fit, and a much closer correspondence was obtained with a 'negative binomial' distribution (arising from a hypothesis that some workers are more liable than others to go sick). The figures are given in Table 8, and show clearly the poor fit of the Poisson distribution. The negative binomial and the observed distributions were compared by a $\chi^{2}$ test, and the result shows that they differ only by chance amounts.

It should be emphasized that this analysis does not necessarily demonstrate the existence of 'sickness proneness' in the specialized sense in which the phrase has come to be used for accidents. It is known in the case of accidents that age, occupation, experience, hours of work and similar factors all influence the liability to accident of the individual worker. These factors act in a similar way on different individuals. Furthermore, if they vary with time in the same individual they lead to corresponding variations in the accident rate of that individual. In this sense they may be regarded as factors 'external' to the worker. However it is found, even in groups of workers for whom all these external factors are the same (i.e. workers " under the same exposure to risk") that the liability to incur 
an accident still differs from individual to individual. It is this more subtle and inherent variation between individuals that is summed up in the phrase ' accident proneness.'

It follows that to obtain convincing evidence on ' sickness proneness' the material analysed should be uniform in such factors as age, occupation and working conditions. The number of sicknesses considered here is unfortunately too small for any subdivision into homogeneous groups to be made. It is true that Table 8 indicates that some workers are more liable than others to ' go sick.' But without an analysis in finer subdivision it is not possible to decide whether this differing liability is wholly accounted for by differences in exposure to risk of the individuals, or whether an inherent 'sicknessproneness ' exists in addition among workers.

A distinction was drawn in the earlier study between frequent absence due to chronic illness ( 9 cases) and that due to 'social irresponsibility' ( 3 cases). The four men in 1946 who had 5 sickness absences, and the one who had 6 absences, were studied in greater detail. (No female had more than 4 absences in the year.)

These five employees all fall into the "chronic illness' group. The man who had 6 absences is a severe asthmatic. Of those with 5 absences, one has severe emphysema, but is a most conscientious worker. Another is frail and anxious, ... with domestic worries; he also wears himself out by doing house-painting and carpentry for gain in his spare time; his absences were from bronchial catarrh and rheumatism, and he has left the factory since 1946. A third is aged 60 and is very prone to rheumatic trouble: he sometimes attends the factory's physiotherapy department. The last has a probable peptic ulcer; despite this digestive trouble he is a good workman and often did overtime during the war. One of his absences was due to an accident at home-a twisted knee. With the exception of the employee who has now. left the firm, all these men have been working in the factory for many years. Such long-term employment is a common feature in factory A.

Stability of labour is in many ways an advantage to a firm. A comparison of the sickness experience of those employed throughout the year in factory $A$ with that of the remainder of the population shows an effect of some interest. The numbers of occurrences of certified sickness per 100 employee-years (not standardized for age) are as follows :

\begin{tabular}{lccc} 
& & \multicolumn{2}{c}{ Employment during.1946 } \\
& & Whole year & Part year \\
Males & $\ldots$ & 39.11 & 53.89 \\
Females & $\ldots$ & $37: 90$ & 63.32
\end{tabular}

The marked difference suggests an association between sickness rates and change of employment. This may be due to a tendency for the less fit to change their work or to be dismissed from it.

\section{Summary and Conclusions}

The investigation was based on the absenteeism due to sickness and accidents in two factories in 1946. The population studied comprised on an average 4,341 males and 743 females, and included weekly and monthly clerical staff as well as production and non-production workers. The records of absence were kept in accordance with the system recommended by the Industrial Health Research Board (Report No. 85) for use in large factories. Certified sickness was classified into seven main groups and seasonal changes were examined.

The main findings were as follows :

1. Those males engaged in production work had a lower incidence of certified sickness, and a lower lost-time rate, than those employed in non-production departments of factory A. It is suggested that

TABLE 8

FREQUENCY DISTRIBUTION OF MALES EMPLOYED THROUGHOUT 1946 ACCORDING TO THE NUMBER OF CERTIFIED SICKNESS ABSENCES IN THAT YEAR : FACTORY A

\begin{tabular}{|c|c|c|c|}
\hline $\begin{array}{c}\text { Number of certified } \\
\text { absences }\end{array}$ & No. of workers & $\begin{array}{c}\text { Expectation } \\
\text { (Poisson) }\end{array}$ & $\begin{array}{c}\text { Expectation } \\
\text { (Negative Binomial) }\end{array}$ \\
\hline $\begin{array}{l}0 \\
1 \\
2 \\
3 \\
4 \\
5 \\
6 \\
7+\end{array}$ & $\left.\begin{array}{r}1633 \\
483 \\
132 \\
29 \\
9 \\
4 \\
1 \\
.0\end{array}\right\} 14$ & $\left.\begin{array}{r}1549.43 \\
605.98 \\
118.50 \\
15.45 \\
1.51 \\
0.12 \\
0.01 \\
0.00\end{array}\right\} 1.64$ & $\left.\begin{array}{r}1636.49 \\
477.05 \\
130.27 \\
34.77 \\
9.18 \\
2.40 \\
0.63 \\
0.21\end{array}\right\} 12.42$ \\
\hline & 2291 & $2291 \cdot 00$ & $2291 \cdot 00$ \\
\hline
\end{tabular}

For the negative binomial distribution, $x^{2}$ with 2 d.f. $=1 \cdot 26 . \quad \cdot 7>P>\cdot 5$. 
this may be due to a selective factor, the less fit men taking the lighter jobs (Tables 2 and 3).

2. Those male clerical workers who were paid weekly had a greater incidence of certified sickness, and a higher lost-time rate, than those who were paid monthly in factory A. It is suggested that this may be due to a combination of socio-economic and occupational factors, though there is a distinct possibility of deficiencies in the sickness recorded among monthly staff.

3. When the causes of certified absence were examined, it was found in both factories that " colds and influenza" had a higher incidence than any other specific group of causes, particularly among females ; but the average duration of absence among males from colds and influenza was less than for other diseases. "Digestive diseases" also had a high incidence. "Nervous disorders" formed the least important group, from the point of view both of lost time and of incidence. This last finding is in marked contrast to recently published work on neurosis among factory workers (Tables 2, 3, and 5).

4. A 'long' absence was defined as one which caused a loss of 30 working days or more during 1946. In factory A the percentage of occurrences which involved a long absence varied from $2 \cdot 1$ per cent. for colds and influenza to 32.8 per cent. for accidents at work. The finding that a lost-time accident frequently disables the worker for a long period stresses anew the importance of active measures to prevent accidents in factories, and the need for further research into predisposing causes (Tabie 5).

5. It is pointed out that the factory management is more interested in a crude sickness rate than in a hypothetical standardized rate, and the differences between the sickness rates of males and females were examined in detail from this standpoint. Among clerical workers in factory $A$ the females had the higher crude and age-specific sickness rates. In the works departments there was little difference (Table 6).

6. Of those employed throughout the year at factory A, 38 per cent. of males and 16 per cent. of females had no sickness absence, certified or uncertified. This difference between the sexes disappears on comparing the percentages who had no certified sickness absence, viz., 71 per cent. of males and 70 per cent. of females (Table 4).

7. Uncertified absence was responsible for between 20 per cent. and 25 per cent. of the time lost from all sickness absence in factory A. Further study is needed on the causes leading to this considerable loss of working time (Table 3).

8. The percentage of possible working time lost from certified sickness in both factories rose to a peak value in February and dropped to a minimum in July, the former figure being more than double the latter (Table 7).

9. As in the previous study, evidence of ' sicknessproneness' is put forward and discussed (Table 8).

We wish to express our thanks to the managements of the two factories for their willing co-operation in this investigation. We are particularly grateful to Miss N. G. Arnold in the personnel department of one of the factories for her valuable assistance in maintaining of one of the factories for her valuable assistance in maintaining sickness returns to the Institute when her department was very short
of staff. We are also indebted to Dr. W. T. Russell for helpful of staff.

\section{REFERENCES}

Bashford, H. (1945), Mon. Bull. Min. Hith. and Emerg. Publ. Hith. Service, 4, 28.

Fraser, R. (1947). " The Incidence of Neurosis among Factory Workers."' Industrial Health Research Board, Report No. 90. Padley, R. (1947). Brit. J. soc. Med., 1, 213.

Russell, W. T., Whitwell, G. P. B., and Ryle, J. A. (1947). Brit. J. industr.' Med., 4, 56.

"The Recording of Sickness Absence in Industry," Industrial Health Research Board, Report No. 85. 